\title{
Xanthophyll $\beta$-cryptoxanthin treatment inhibits hepatic steatosis without altering vitamin A status in $\beta$-carotene 9',10'-oxygenase knockout mice
}

\author{
Chun Liu", Bruna Paola M. Rafacho", Xiang-Dong Wang \\ Nutrition and Cancer Biology Laboratory, JM USDA Human Nutrition Research Center on Aging at Tufts University, Boston, MA, USA \\ Contributions: (I) Conception and design: XD Wang, C Liu; (II) Administrative support: XD Wang; (III) Provision of study materials or patients: XD \\ Wang; (IV) Collection and assembly of data: All authors; (V) Data analysis and interpretation: All authors; (VI) Manuscript writing: All authors; (VII) \\ Final approval of manuscript: All authors. \\ \#These authors contributed equally to this work. \\ Correspondence to: Xiang-Dong Wang, MD, PhD. Nutrition and Cancer Biology Laboratory, JM USDA Human Nutrition Research Center on Aging \\ at Tufts University, 711 Washington Street, Boston, MA 02111, USA. Email: xiang-dong.wang@tufts.edu.
}

Background: $\beta$-cryptoxanthin (BCX), one of the major carotenoids detected in human circulation, can protect against the development of fatty liver disease. BCX can be metabolized through $\beta$-carotene-15,15'oxygenase (BCO1) and $\beta$-carotene-9',10'-oxygenase (BCO2) cleavage pathways to produce both vitamin A and apo-carotenoids, respectively, which are considered important signaling molecules in a variety of biological processes. Recently, we have demonstrated that BCX treatment reduced hepatic steatosis severity and hepatic total cholesterol levels in both wide type and $\mathrm{BCO} 1^{-/} / \mathrm{BCO}^{-/-}$double knock out $(\mathrm{KO})$ mice. Whether the protective effect of $\mathrm{BCX}$ is seen in single $\mathrm{BCO} 2^{-/} \mathrm{KO}$ mice is unclear.

Methods: In the present study, male $\mathrm{BCO} 2^{-/} \mathrm{KO}$ mice at 1 and 5 months of age were assigned to two groups by age and weight-matching as follows: (I) -BCX control diet alone (AIN-93 purified diets); (II) +BCX $10 \mathrm{mg}$ (supplemented with $10 \mathrm{mg}$ of BCX/kg of diet) for 3 months. At 4 and 8 months of age, hepatic steatosis and inflammatory foci were evaluated by histopathology. Retinoids and BCX concentrations in liver tissue were analyzed by high-performance liquid chromatography (HPLC). Hepatic protein expressions of SIRT1, acetylated and total FoxO1, PGC1 $\alpha$, and PPAR $\alpha$ were determined by the Western blot analysis. Real-time PCR for gene expressions (MCAD, SCD1, FAS, TNF $\alpha$, and $I L-1 \beta$ gene expression relative to $\beta$-actin) was conducted in the liver.

Results: Steatosis was detected at 8 months but not at 4 months of age. Moreover, BCX supplementation significantly reduced the severity of steatosis in the livers of $\mathrm{BCO} 2 \mathrm{KO}$ mice, which was associated with changes in hepatic SIRT1 acetylation of FOXO1, PGC1 $\alpha$ protein expression and PPAR $\alpha$ protein expression in $\mathrm{BCO}^{-/-} \mathrm{KO}$ mice. HPLC analysis showed that hepatic BCX was detected in BCX supplemented groups, but there were no differences in the hepatic levels of retinol and retinyl palmitate (RP) among all groups.

Conclusions: The present study provided experimental evidence that BCX intervention can reduce liver steatosis independent of BCO2.

Keywords: $\beta$-cryptoxanthin (BCX); oxygenases; fatty liver

Submitted Mar 29, 2020. Accepted for publication Jul 03, 2020.

doi: $10.21037 / \mathrm{hbsn}-20-404$

View this article at: http://dx.doi.org/10.21037/hbsn-20-404 


\section{Introduction}

Observational epidemiological studies have indicated that increased dietary intake of carotenoids may protect against the development of several chronic and degenerative diseases, including liver diseases (1-4). Carotenoids can be grouped in provitamin A carotenoids, like $\alpha$-carotene, $\beta$-carotene and $\beta$-cryptoxanthin (BCX), or non-provitamin A carotenoids, like lycopene, lutein and zeaxanthin, depending on their ability to be metabolized to the essential nutrient vitamin A. The structure of carotenoids contains a series of conjugated double bonds, which makes them susceptible to oxidative cleavage $(5,6)$. Oxidative cleavage of carotenoids results in the formation of apo-carotenoid metabolites, important signaling molecules with biological roles different than their parent compound (7). Two major carotenoid cleavage oxygenases have been well characterized, $\beta$-carotene-15,15'-oxygenase (BCO1), which produces vitamin $A$, and $\beta$-carotene-9',10'-oxygenase (BCO2), which produces apocarotenoids, from both provitamin $\mathrm{A}$ and non-provitamin A carotenoids. Besides their role in carotenoids metabolism, recent research has attributed BCOs a more diversified role in health, with special relation to lipid metabolism (BCO1) (3). These data indicate a complex interaction between carotenoids metabolism and health, and the better understanding of this relation is of great importance.

BCX is one of the major carotenoids detected in human circulation $(1,2)$. BCX is an oxygenated carotenoid (xanthophyll), found at high levels in citrus fruits, pumpkin and red peppers (8). BCX intake has been inversely associated with adiposity, oxidative DNA damage, lipid peroxidation and inflammation (8-13) and it is the only carotenoid whose dietary intake was inversely associated with the risk of lung cancer (14). The exact mechanism of this protective effect is unclear, since $\mathrm{BCX}$ can be cleaved by $\mathrm{BCO} 1$ and $\mathrm{BCO} 2$, suggesting a multifaceted biological action. A recent study from our laboratory suggested that the BCX inhibits inflammation and liver tumor development independent of BCO1/ BCO2 $(15,16)$.

Given the importance of $\mathrm{BCO} 2$ in carotenoid metabolism and the protective action of $\mathrm{BCX}$, the aim of the present study is to evaluate the effect of BCX supplementation on hepatic steatosis and inflammation in $\mathrm{BCO} 2$ knockout mice and determine whether the $\mathrm{BCX}$ action is dependent of $\mathrm{BCO} 2$. We present the following article in accordance with the ARRIVE reporting checklist (available at https://hbsn. amegroups.com/article/view/10.21037/hbsn-20-404/rc).

\section{Methods}

\section{Animals, diet and experimental groups}

$\mathrm{BCO}^{-/-}$knock out $(\mathrm{KO})$ mice with $\mathrm{BCO} 2$ gene ablation, which were provided by Dr. Johannes von Lintig (Case Western Reserve University), were used for the present study and the generation of these mice has been previously described (17). Study mice were fed to the standard laboratory chow (Harlan Laboratories, MA, USA) until experiment begin, and maintained on a 12-hour light/dark cycle in a controlled temperature and humidity room, and given AIN-93 purified diets and water ad libitum.

Two groups of male $\mathrm{BCO} 2^{-/-} \mathrm{KO}$ mice at 1 month $(\mathrm{n}=13$ in the control group; $\mathrm{n}=14$ in the BCX group) and 5 months ( $n=5$ per group) of age were assigned to two treatments by age and weight-matching for 3 months, respectively, as follows (I) -BCX [control diet (AIN-93M purified rodent diet powder, Harlan Laboratories Inc., Madison, WI, USA)]; (II) +BCX $10 \mathrm{mg}$ (control diet supplemented with $10 \mathrm{mg}$ of BCX/kg of diet). All study mice were given fresh diets every 2-3 days, and maintained on their respective diets until the experiment was completed. Mice in these four groups were weighed weekly and euthanized at 4 and 8 months of age, respectively, by exsanguinations under deep anesthesia without fasting. Steatosis was not observed in two groups of 4-month old mice and the objective of this study was to evaluate the effect of BCX on liver steatosis and the underlying mechanism of the BCX effect; therefore, only 8 -month old mice were used to evaluate the effect of BCX supplementation on molecular mechanism in this study.

Experiments were performed under a research protocol (No. H2018-118) with approval of the Institutional Animal Care and Use Committee at the Jean Mayer USDA Human Nutrition Research Center on Aging at Tufts University, in accordance with the National Institutes of Health Guide for the Care and Use of Laboratory Animals.

\section{BCX supplementation}

BCX ( $>99 \%$ purity, BASF) in powder form was directly mixed with the standard AIN-93 M purified rodent diet powder at the concentration of $10 \mathrm{mg} / \mathrm{kg}$ of diet, as conducted previously (12). Briefly, based on 
previous information of absorption of carotenoids in rodents and humans $(12,18,19), 10 \mathrm{mg} / \mathrm{kg}$ diet of BCX in this mouse study was equivalent to a daily human consumption of $0.87 \mathrm{mg}$. Specifically, as stated in our previous publication (12), the absorption of carotenoids in rodents is approximately one-seventh that in humans and

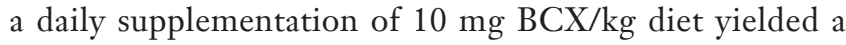
serum concentration of $\mathrm{BCX}$ of $9.9 \mu \mathrm{g} / \mathrm{L}$ in mice and the absorption of BCX in humans is approximately $8 \%$ of what is consumed (a diet containing 1,300 $\mu \mathrm{g}$ BCX yielded a serum concentration of $113 \mu \mathrm{g} / \mathrm{L}$ ). Therefore, the dose of BCX $(10 \mathrm{mg} / \mathrm{kg}$ diet $)$ in this mouse study was equivalent to daily human intake of $0.87 \mathrm{mg}[9.9 \mu \mathrm{g} / \mathrm{L} \times 7 \times(100 \% / 8 \%)$ $=866.25 \mu \mathrm{g} \approx 0.87 \mathrm{mg}$. This dose can be obtained from dietary citrus fruits, such as consuming three raw tangerines daily (20). Thus, the dose of BCX supplementation used here is within the physiologic range (12).

\section{Histopathological evaluation of liver lesions}

Five $\mu \mathrm{m}$ sections of formalin-fixed, paraffin-embedded liver tissue were stained with hematoxylin and eosin (H\&E) for histopathological examination. Two independent investigators blinded to treatment groups examined the sections under light microscopy. Hepatic steatosis was graded according to the magnitude of steatosis (both macroand micro-vesicular fat accumulation) and the degree of liver inflammation severity as described previously (21). Briefly, the degree of steatosis was graded 0-4 (grading $0=<5 \%, 1=5-25 \%, 2=26-50 \%, 3=51-75 \%, 4=>75 \%)$, based on the average percentage area of the liver section that was occupied by fat vacuoles per field at $100 \times$ magnification under H\&E staining in 20 random fields. Inflammatory foci were evaluated by the number of inflammatory cell clusters in 20 random fields at 100× magnification, which mainly constitute mononuclear inflammatory cells. Twenty fields of view at 100 magnification represent $0.63 \mathrm{~cm}^{2}$, and inflammatory foci counts were represented as the number of foci per $\mathrm{cm}^{2}$. A ZEISS microscope with a PixeLINK USB 2.0 (PL-B623CU) Digital Camera and PixeLINK $\mu$ Scope Microscopy Software was used for image capture of all histopathological examinations.

\section{Protein isolation and Western blotting}

Whole-cell lysates of liver tissues were prepared as previously described (22). The following antibodies were used for Western blotting: SIRT1 (sc-74465), acetylated and total FOXO1 (sc-374427), PGC1 $\alpha$ (sc-518025), and PPARa (sc-398394) (Santa Cruz Biotechnology, Inc.), and glyceraldehyde-3-phosphate dehydrogenase (GAPDH) (MAB374) (Millipore). All antibodies were used according to the manufacturers' protocols. Blots were developed using the ECL Western Blotting system (Amersham) and analyzed with a densitometer (GS-710 calibrated imaging densitometer, Bio-Rad).

\section{$R N A$ extraction and quantitative real-time PCR (qRT- PCR)}

mRNA levels of $S C D 1, F A S, M C A D, T N F \alpha$ and $I L-1 \beta$ were determined by qRT-PCR. Liver and mesenteric adipose tissue RNA was extracted using TriPure reagent (Roche Applied Science) according to the manufacturer's instructions and cDNA was synthesized using random primer Moloney murine leukemia virus reverse transcriptase (Invitrogen). qRTPCR was performed using the SYBR Green qRTPCR kit (Invitrogen) according to the manufacturer's instructions on an Applied Biosystems 7500 sequence detection system. For liver analysis, primer sequences were: SCD1 forward AGAGAGAGAGGTAGCCATATC and reverse TCAAATCTCACTAATCTCTGG; FAS forward CCCTTGATGAAGAGGGATCA and reverse ACTCCACAGGTGGGAACAAG; $M C A D$ forward GATGCATCACCCTCGTGTAAC and reverse AAGCCCTTTTCCCCTGAAG; $T N F \alpha$ forward CTGAGGTCAATCTGCCCAAGTAC and reverse CTTCACAGAGCAATGACTCCAAAG; and $I L-1 \beta$ forward AGCCAAGCTTCCTTGTGCAAGTGT and reverse GCAGCCCTTCATCTTTTGGGGTCC. For adipose tissues, primer sequences were: Acox3; UCP3; SCD1, Adiponectin forward GTGATGGCAGAGATGGCAC and reverse GCCTTGTCCTTCTTGAAGAG; for PPAR $\gamma$ forward ATCGTGGGCCGCCCTAGGCA and reverse TGGCCTTAGGGTTCAGAGGGG. Relative gene expression adjusted to $\beta$-actin was determined using the $2^{-\Delta \Delta C T}$ method as described previously (23), and expressed as fold change. $\beta$-actin sequence primer sequences were forward ACGGCCAGGTCATCACTATTG and reverse TGGAAAAGAGCCTCAGGGC.

\section{High-performance liquid chromatography (HPLC)}

The livers samples for HPLC analysis were prepared 
Table $1 \mathrm{BW}$ and hepatic concentrations of BCX and retinoids (retinol and RP) in BCO2-KO mice at 4 and 8 months old that were fed with the control or BCX diet for 3 months

\begin{tabular}{lcccc}
\hline \multirow{2}{*}{ Group } & \multicolumn{2}{c}{4 months old } & \multicolumn{2}{c}{8 months old } \\
\cline { 2 - 5 } & -BCX $(\mathrm{n}=13)$ & $+\mathrm{BCX} 10 \mathrm{mg} / \mathrm{kg}$ diet $(\mathrm{n}=14)$ & $-\mathrm{BCX}(\mathrm{n}=5)$ & $+\mathrm{BCX} 10 \mathrm{mg} / \mathrm{kg}$ diet $(\mathrm{n}=5)$ \\
\hline Initial BW $(\mathrm{g})$ & $17.0 \pm 1.6$ & $17.0 \pm 1.6$ & $23.1 \pm 2.0$ & $21.8 \pm 0.9$ \\
Final BW $(\mathrm{g})$ & $23.3 \pm 2.1$ & $23.9 \pm 2.9$ & $\mathrm{ND}$ & $28.5 \pm 2.0$ \\
BCX $(\mathrm{nmol} / \mathrm{g})$ & $\mathrm{ND}$ & $0.54 \pm 0.12^{\mathrm{a}}$ & $26.7 \pm 12.4$ & $0.64 \pm 0.18^{\mathrm{a}}$ \\
Retinol $(\mathrm{nmol} / \mathrm{g})$ & $25.2 \pm 10.6$ & $27.9 \pm 13.4$ & $4,185 \pm 823$ & $31.2 \pm 16.9$ \\
RP $(\mathrm{nmol} / \mathrm{g})$ & $4,161 \pm 815$ & $4,295 \pm 560$ & $30.7 \pm 6.4^{\mathrm{b}}$ & $4,340 \pm 370$ \\
TG $(\mathrm{mg} / \mathrm{g})$ & $15.2 \pm 8.6^{\mathrm{a}}$ & $12.9 \pm 7.4^{\mathrm{a}}$ & $12.2 \pm 6.9^{\mathrm{a}}$ \\
\hline
\end{tabular}

Values are expressed as means \pm SD (ANOVA overall F-test followed by Tukey's honest test). ${ }^{\text {a }}$, For a given row, under the same age group, data not sharing a common superscript letter are statistically significantly different at $\mathrm{P} \leq 0.05$. BCX, $\beta$-cryptoxanthin; $\mathrm{BCO}$, $\beta$-carotene-9',10'-oxygenase; KO, knock out; BW, body weight; RP, retinyl palmitate; TG, triglycerides; ND, not detected; SD, standard deviation.

as previously described $(10,12)$. Specifically, a total of $0.1 \mathrm{~g}$ of tissue (wet weight) was homogenized (30 seconds) with internal standards [echinenone $(50 \mu \mathrm{L})$ and retinyl acetate $(50 \mu \mathrm{L})]$ and $1 \mathrm{~mL}$ of normal saline (1 minute). After the addition of $5 \mathrm{~mL}$ of $\mathrm{CHCl} / \mathrm{CH} 3 \mathrm{OH}(2: 1$, $\mathrm{v} / \mathrm{v}$ ), the mixture was homogenized again (30 seconds) and then vortexed ( 1 minute) and centrifuged for 10 minutes at $800 \times \mathrm{g}$ at $4{ }^{\circ} \mathrm{C}$. After the lower layer of $\mathrm{CHCl} 3$ was collected, hexane $(5 \mathrm{~mL})$ was added to the remaining sample; the mixture was again mixed on a vortex (1 minute) and centrifuged for another 10 minutes at 2,000 $\times \mathrm{g}$ at $4{ }^{\circ} \mathrm{C}$. The upper layer of hexane was collected. The chloroform and hexane layers were combined and evaporated under $\mathrm{N} 2$, after which they were reconstituted with $50 \mu \mathrm{L}$ of ethanol and ether $(2: 1)$. A $50-\mu \mathrm{L}$ aliquot of the extract reconstituted was injected onto the HPLC. A gradient reverse-phase HPLC system consisting of a Waters 2695 separation module and a Waters 2998 photodiode array detector was used for the detection of BCX, retinol, and retinyl palmitate (RP). Briefly, BCX, retinol, and RP were analyzed on a reverse-phase C18 column $(4.6 \times 250 \mathrm{~mm}$, 5 mm; Vydac 201TP54, Grace Discovery Sciences, Inc.) with a flow rate of $1.00 \mathrm{~mL} / \mathrm{min}$ and quantified relative to an internal standard by determining the peak areas against known amounts of standards. BCX and retinoids (retinol and RP) were identified by co-elution with standards and quantified relative to the internal standards (echinenone for BCX and retinyl acetate for retinol and RP), by determining peak areas calibrated against known amounts of standards.

\section{Statistical analysis}

Data were presented as mean \pm standard deviation $(\mathrm{SD})$ for animal weights, liver inflammatory foci, liver BCX and retinoids concentrations, or as mean \pm standard error of the mean (SEM) for mRNA and protein levels, and statistical differences among groups were determined by one-way ANOVA. Steatosis grade (ordinal variable) was presented as medians (grading range), and Kruskal-Wallis overall test followed by Wilcoxon rank-sum test was used to test for statistical significance among groups. SAS, version 9.2 (SAS Institute, Cary, NC, USA) was used for all statistical analyses. All $\mathrm{P}$ values were set at the significance level of $\alpha=0.05$ ( $\mathrm{P}$ value $\leq 0.05$ ).

\section{Results}

\section{Body weights (BWs) and concentrations of $B C X$ and retinoids}

BWs did not differ between groups at the same age at the beginning or end of the study (Table 1). After 3 months of treatment, hepatic retinol and RP did not differ between groups. BCX was not detected in the liver of $-\mathrm{BCX}$ group, but was detected after BCX supplementation in the + BCX $10 \mathrm{mg}$ groups. BCX supplementation at the dose of $10 \mathrm{mg} / \mathrm{kg}$ of diet significantly increased hepatic BCX concentrations as compared with the $-\mathrm{BCX}$ group (Table 1). 

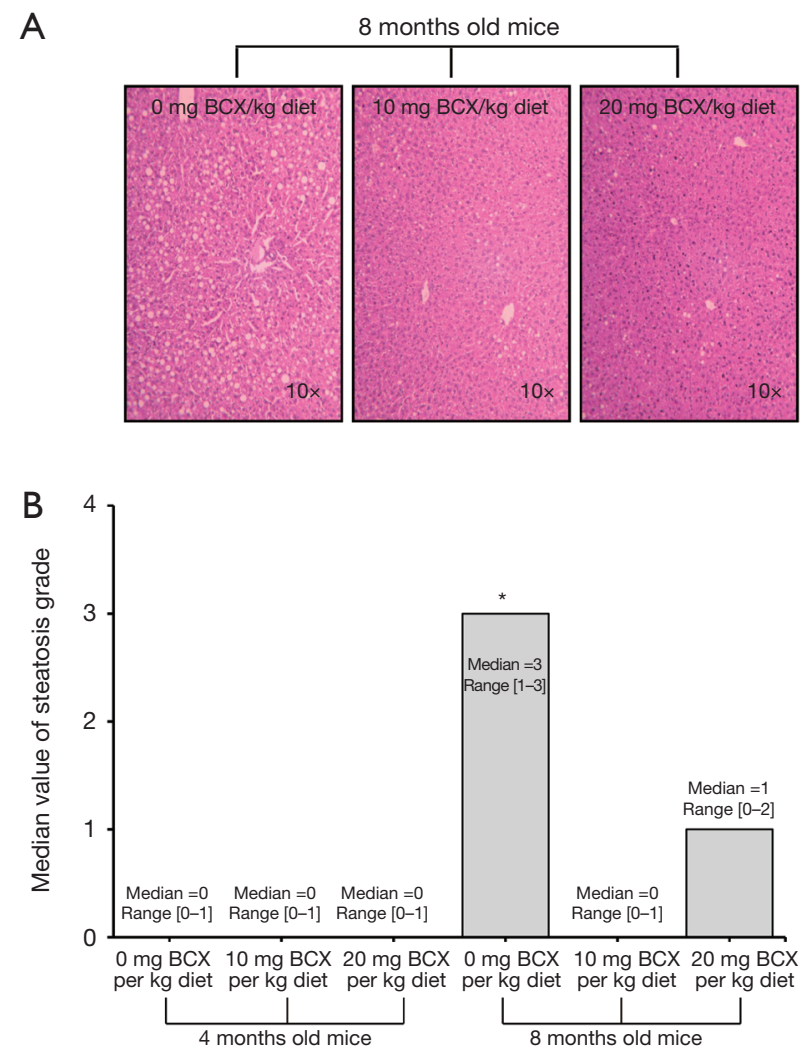

Figure 1 Representative $\mathrm{H} \& \mathrm{E}$ stained sections of livers of hepatic steatosis in BCO2-KO mice at 8 months old fed control or BCX diet (A) and the comparison of median of steatosis score among groups (B). *, median score differed from that of the -BCX group, $\mathrm{P} \leq 0.05$. H\&E, hematoxylin and eosin; $\mathrm{BCO} 2, \beta$-carotene-9',10'oxygenase; $\mathrm{KO}$, knock out; $\mathrm{BCX}, \beta$-cryptoxanthin.

\section{Hepatic steatosis and inflammatory foci}

Severe hepatic steatosis was observed in the $\mathrm{BCO} 2^{-/-}$ $\mathrm{KO}$ mice at 8 months old without BCX supplementation as compared with that of BCX supplemented groups (Figure 1A). The steatosis ranged from grade 1 to 3 with the median value of 3 and no mice had grade 0 in the $-\mathrm{BCX}$ group (Figure 1B). BCX supplementation significantly reduced steatosis. In the $+\mathrm{BCX} 10 \mathrm{mg}$ group, the steatosis grade ranged from 0 to 1 with the median value of 0 and no mice had grade 2 or 3 of steatosis score (Figure $1 B$ ). Similarly, BCX supplementation also significantly reduced hepatic levels of triglycerides (TG) at 8 months (Table 1). Hepatic inflammatory foci as represented in Figure $2 A$ were detected in all groups, and inflammatory foci were lower in the BCX supplemented group, though the differences were not statistically significant (Figure 2B).

\section{Hepatic SIRT1 expression and activity, PGC1 and PPAR expression}

Hepatic SIRT1 protein expression was not different between the groups (Figure 3A). Acetylated FOXO1 expression, a well-known target of SIRT1, was significantly lower in the $+\mathrm{BCX}$ group after BCX supplementation as compared with the $-\mathrm{BCX}$ group, indicating that hepatic SIRT1 deacetylase activity was induced by BCX (Figure $3 B$ ). Hepatic PGC1 $\alpha$ protein expression, another SIRT1 target, was higher in the $+\mathrm{BCX}$ group in comparison with the $-\mathrm{BCX}$ group (Figure 3C). Hepatic PPAR $\alpha$ protein expression was also higher in the $+\mathrm{BCX}$ group as compared with the $-\mathrm{BCX}$ group (Figure 3D).

\section{Expression of genes involved in lipid metabolism and inflammation}

The hepatic FAS and SCD1 gene expressions were lower in the $+\mathrm{BCX}$ group (Figure $4 A, B$ ), and the hepatic gene expression of $M C A D$ was higher in the $+\mathrm{BCX}$ group (Figure $4 C$ ) in comparison to the $-\mathrm{BCX}$ group. No differences in the hepatic $T N F \alpha$ and $I L-1 \beta$ mRNA expression were observed between the groups (data not shown). Mesenteric adipose tissue gene expression for Adiponectin, Acox3, and SCD1 did not differ between the groups (data not shown). For PPAR $\gamma$ in the mesenteric adipose tissue, BCX treatment marginally increased the gene expression in the $+\mathrm{BCX}$ group in comparison to the - BCX group (Figure 4D).

\section{Discussion}

The present study shows that $\mathrm{BCO} 2^{-/-} \mathrm{KO}$ mice fed with a vitamin A sufficient diet [AIN-93M purified diet (\% $\mathrm{kcal}$ from carbohydrate, protein and fat: $76 \%, 13.8 \%$ and $10.2 \%$, respectively)] without carotenoid supplementation developed liver steatosis at 8 months old but not at 4 months old. This finding suggests that the occurrence of steatosis is related to age of the mice in the $\mathrm{BCO}^{-1-}$ $\mathrm{KO}$ mice, which is consistent with the result from the study by Hessel et al. (24) that studied BCO1 knockout mice with different ages and found that BCO1 deficient mice developed fatty liver independent of the vitamin A or carotenoids content of the diet. The authors also described that steatosis was more pronounced with age (24), supporting our findings that steatosis was only detected in mice with 8 months old, and not at 4 months old. In fact, 
A

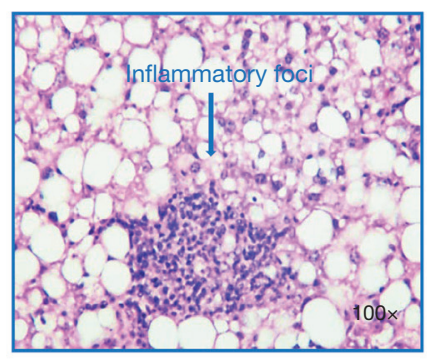

B

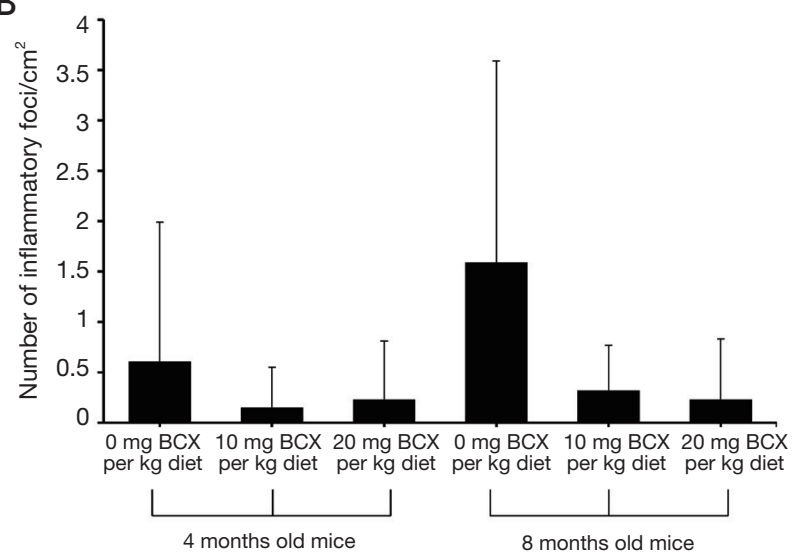

Figure 2 Insert: representative inflammatory foci as seen on a $\mathrm{H} \& \mathrm{E}$ stained slide (A) and the number of inflammatory foci in BCO2-KO mice at 4 and 8 months old fed control or BCX diet (B). Values are mean \pm SD. H\&E, hematoxylin and eosin; BCO2, $\beta$-carotene-9',10'-oxygenase; KO, knock out; BCX, $\beta$-cryptoxanthin; SD, standard deviation.

aging has been associated with increased accumulation of lipids in non-adipose tissue organs, like the liver (25). Furthermore, our finding in $\mathrm{BCO}^{-/-} \mathrm{KO}$ mice aged 4 months old is also consistent with the result from the study by Amengual et al. (17) described no steatosis was observed in $\mathrm{BCO}_{2}{ }^{-/} \mathrm{KO}$ mice at $\sim 3$ months (13 weeks) of age, that were fed standard chow diet $(60 \%, 28 \%$, and $12 \%$ of the $\% \mathrm{kcal}$ from carbohydrate, protein, and fat, respectively) without carotenoid supplementation. These data suggest that despite the different diets used in these two studies, $\mathrm{BCO}^{-/-} \mathrm{KO}$ mice aged 3-4 months old did not developed steatosis. The liver steatosis developed in $\mathrm{BCO}^{-{ }^{--}} \mathrm{KO}$ mice aged 8 months old could be in part due to age of animals. However, due to the lack of wild type of mice, we cannot exclude the possibility of steatosis development was due to $\mathrm{BCO} 2 \mathrm{KO}$. A recent study that showed that $\mathrm{BCO} 2$ genotype affects mitochondrial functioning and energy homeostasis (26) provided the evidence that the $\mathrm{BCO} 2$ genotype may play a role in liver steatosis. But, importantly, in this study, BCX supplementation significantly reduced the severity of liver steatosis in the $\mathrm{BCO}^{-/-} \mathrm{KO}$ mice with no effect on hepatic retinoid levels. Retinoids have been associated with improved steatosis and metabolism regulation in the liver (27-29). Since apo-carotenoid, metabolites of BCO2 can be further cleaved by BCO1 to generating vitamin A (30), our findings suggest that BCX itself exerted a protective effect. This is corroborated by our recent study with BCX supplementation in fatty liver and hepatocellular carcinoma in mice, in which $\mathrm{BCX}$ was effective in preventing those outcomes $(12,15,16,31)$. By contrast, in the study by Amengual et al. (17), severe liver steatosis was developed in BCO2-KO mice at $~ 3$ months (13 weeks) of age after feeding a vitamin A-deficient purified diet (based on AIN$93 \mathrm{G}$ formulation) supplemented with $50 \mathrm{mg} / \mathrm{kg}$ lutein or $50 \mathrm{mg} / \mathrm{kg}$ zeaxanthin. The authors attribute liver steatosis to hepatic mitochondria stress and dysfunction due to the accumulation of carotenoids metabolites (17). Despite the same genetic background, the dose used in the study by Amengual et al. (17) was 5 times higher than the dose used in our study, and carotenoid used was also different. Ford et al. (32) studied hepatic lipid accumulation in wild type, BCO1 and BCO2 knockout female mice at 7 months old fed with chow diet, lycopene supplemented diet or tomato powder supplemented diet and found that $\mathrm{BCO} 2$ knockout mice displayed higher lipids content in the liver, but not steatosis, in comparison to wild type mice, independently of the diet consumed. The authors also evaluated inflammatory markers, but found no differences between groups (32). Taken together, these data suggest that impaired lipid metabolism may explain the presence of steatosis observed in the present study. Additionally, no effect of BCX supplementation on retinoid levels in this study confirms recent reports that showed that BCX is $\mathrm{BCO} 2-$ dependently converted to retinoids and that $\mathrm{BCO} 2$ is the major BCX metabolizing enzyme in mice (33).

It is also important to highlight that the BCX dose used in this study was relevant to physiologic levels. First, data from our previous study showed that the detected BCX serum concentration in $\mathrm{A} / \mathrm{J}$ mice supplemented with $10 \mathrm{mg} \mathrm{BCX} / \mathrm{kg}$ diet was lower than that of the average U.S. population (12). Second, the mean liver BCX concentration in the mice supplemented with $10 \mathrm{mg} \mathrm{BCX} / \mathrm{kg}$ diet in this study $(0.64 \mathrm{nmol} / \mathrm{g})$ was comparable to that reported in human livers $(0.66 \mathrm{nmol} / \mathrm{g})$ (34). Furthermore, the BCX 
A

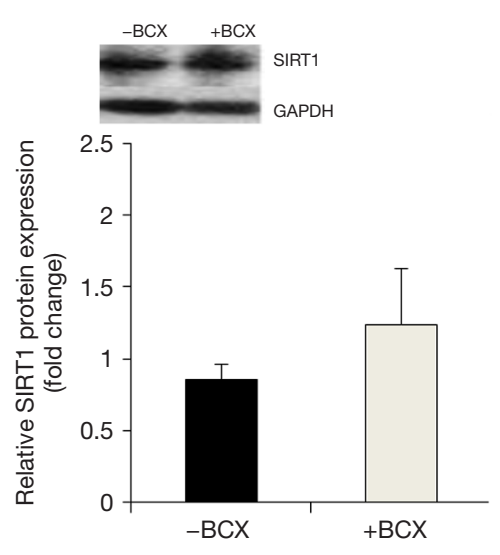

C

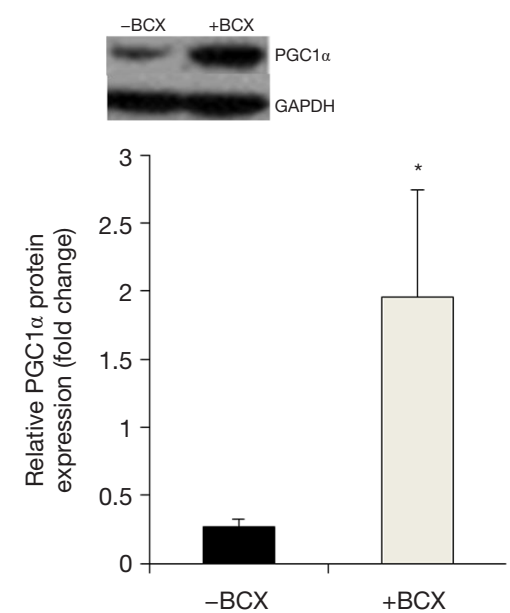

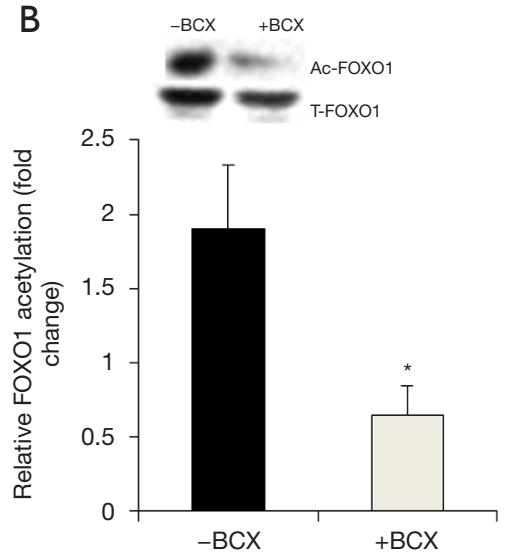

D

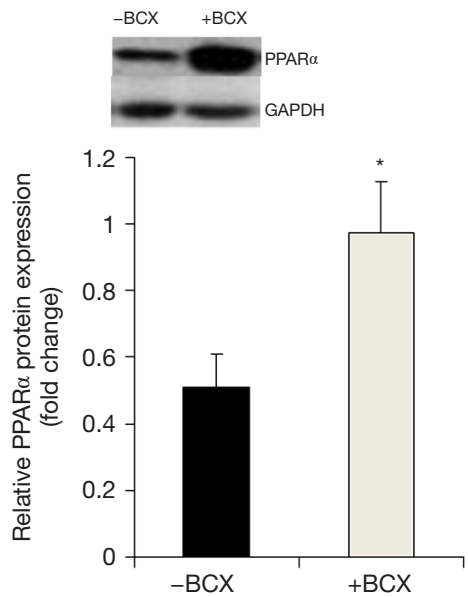

Figure 3 Hepatic SRT1 protein expression (A), acetylation of FOXO1 (B), PGC1 $\alpha$ protein expression (C), and (D) PPAR $\alpha$ protein expression in $\mathrm{BCO} 2-\mathrm{KO}$ mice fed control or $\mathrm{BCX}$ diet for 3 months. Values are mean $\pm \mathrm{SEM}, \mathrm{n}=5$. *, different from $-\mathrm{BCX}, \mathrm{P} \leq 0.05$. $\mathrm{BCO} 2$, $\beta$-carotene-9',10'-oxygenase; KO, knock out; BCX, $\beta$-cryptoxanthin; SEM, standard error of the mean.

dose used in the present study, which was equivalent to daily human consumption of $0.87 \mathrm{mg}$ of BCX, can be obtained from dietary citrus fruits, such as consuming three raw tangerines daily $(15,16,31)$.

In the present study, the significant reduction in hepatic fat accumulation by BCX was associated with the induction of SIRT1 activity and upregulation of PGC1 $\alpha$ and PPAR $\alpha$ in the liver tissue of BCO2-KO mice. BCX significantly decreased the levels of acetylated FOXO1, indicating an increase in SIRT1 enzyme activity by BCX supplementation. We and others have shown that SIRT1 activation can protect liver against fat accumulation (35-38). The mechanisms by which SIRT1 activation may attenuate steatosis include the deacetylation and inactivation of
SREBP-1c and the promotion of deacetylation and activation of PGC1 $\alpha(39,40)$. Hepatic lipogenesis is mainly regulated by SREBP-1c, which increases the expression of lipogenic genes such as FAS and SCD1. FAS is a ratelimiting enzyme in the fatty acid biosynthesis and catalyzes the last step of de novo lipogenesis, and SCD1 catalyzes the formation of monounsaturated long-chain fatty acids. Previously, the depletion of SCD1 in obese mice resulted in the reversal of hepatic steatosis (41). In this context, increased SIRT1 activity can lead to SREBP-1c downregulation, suppressing lipogenic genes expression, contributing to reducing hepatic steatosis (42). On the other hand, the activation of PGC1 $\alpha$ may increase the PPAR $\alpha$ mediated gene expression, like fatty acid oxidizing enzymes 
A

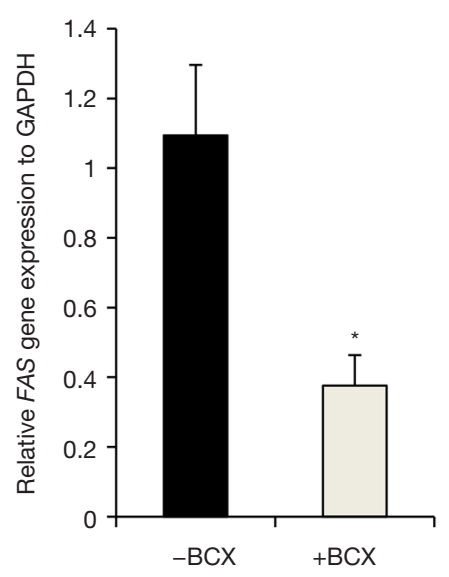

C

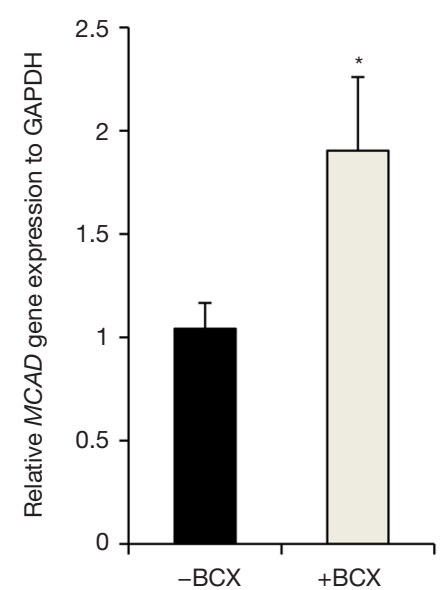

B

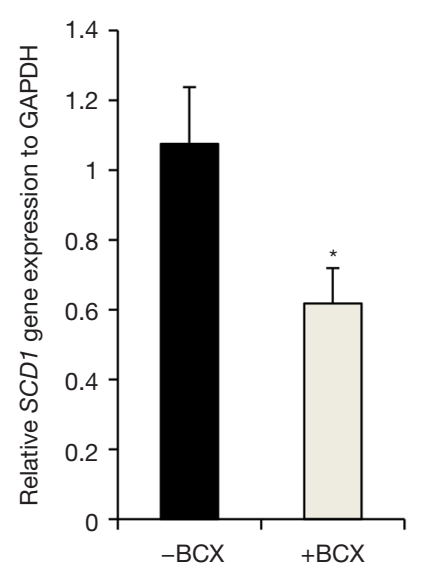

D

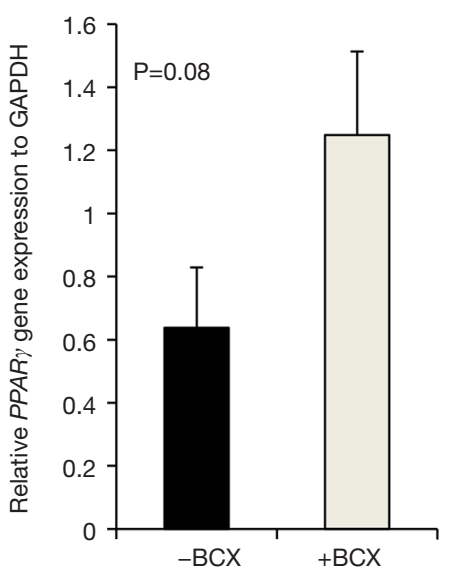

Figure 4 Hepatic FAS mRNA (A), SCD1 mRNA (B), MCAD mRNA (C), and adipose tissue PPAR mRNA (D) in BCO2-KO mice fed control or BCX diet for 3 months. Values are mean $\pm \mathrm{SEM}, \mathrm{n}=5$. * , different from $-\mathrm{BCX}, \mathrm{P} \leq 0.05$. BCO2, $\beta$-carotene- $9^{\prime}, 10^{\prime}$-oxygenase; KO, knock out; BCX, $\beta$-cryptoxanthin; SEM, standard error of the mean.

such as very long-chain (ACADVL) and MCAD (43-45). These dehydrogenases are involved in the first step of the $\beta$-oxidation, and are responsible for the dehydrogenation of the acyl-CoA ester. Indeed, the deficiency of MCAD and ACADVL was associated with hepatic steatosis in mice, supporting their role in the fatty acid $\beta$-oxidation in the liver (41). In the present study, BCX increased SIRT1 activity/PGC1 $\alpha$-PPAR $\alpha$ expression, which was associated with both inhibition of fatty acid synthesis genes FAS and SCD1 and up-regulation of fatty acid oxidation gene MCAD in the liver of BCO2-KO mice. In the mesenteric adipose tissue, no difference in lipid metabolism markers was observed. PPAR $\gamma$ in adipose tissue was marginally increased after BCX treatment. The activation of PPAR $\gamma$ stimulates the storage of fatty acids in mature adipocytes, contributing to reduced lipotoxicity (46). Taken together, these data suggest that BCX itself protects against the development of steatosis in $\mathrm{BCO} 2-\mathrm{KO}$ mice by targeting hepatic SIRT1 activity and downregulating hepatic lipid synthesis, and upregulating hepatic fatty acid oxidation. The upregulation of SIRT1 activity and PPAR $\alpha$ expression is in accordance with previous studies $(11,12,47)$. However, the mechanism by which BCX increases SIRT1 remains to be further explored.

In summary, BCX itself induced hepatic SIRT1 activity, activating SIRT1/PGC1 $\alpha / \mathrm{PPAR} \alpha$ signaling pathway and inhibiting hepatic lipogenesis that ultimately led to decreased hepatic steatosis. The present study raised 
important points about gene-diet interaction between the BCO2 enzyme and dietary carotenoids. First, it supports previous observations that the aging process is related to lipid metabolism alterations in the liver. Second, given that the single-nucleotide polymorphism (SNP) in the $B C O 2$ gene has been reported and associated metabolic alterations in humans (3), the present study suggests that BCX at physiologic levels may exert biological function and activate SIRT1 pathways in the absence of $\mathrm{BCO} 2$.

\section{Acknowledgments}

Any opinions, findings, conclusion, or recommendations expressed in this publication are those of the authors and do not necessarily reflect the view of the U.S. Department of Agriculture.

Funding: This work was supported by grants from NIFA/ AFRI (2017-67017-26363) and USDA/ARS (58-19500074S).

\section{Footnote}

Reporting Checklist: The authors have completed the ARRIVE reporting checklist. Available at https://hbsn. amegroups.com/article/view/10.21037/hbsn-20-404/rc

Data Sharing Statement: Available at https://hbsn. amegroups.com/article/view/10.21037/hbsn-20-404/dss

Conflicts of Interest: All authors have completed the ICMJE uniform disclosure form (available at https://hbsn. amegroups.com/article/view/10.21037/hbsn-20-404/coif). XDW serves as the unpaid Deputy Editor-in-Chief of Hepatobiliary Surgery and Nutrition. The other authors have no conflicts of interest to declare.

Ethical Statement: The authors are accountable for all aspects of the work in ensuring that questions related to the accuracy or integrity of any part of the work are appropriately investigated and resolved. Experiments were performed under a research protocol (No. H2018118) with approval of the Institutional Animal Care and Use Committee at the Jean Mayer USDA Human Nutrition Research Center on Aging at Tufts University, in accordance with the National Institutes of Health Guide for the Care and Use of Laboratory Animals.

Open Access Statement: This is an Open Access article distributed in accordance with the Creative Commons Attribution-NonCommercial-NoDerivs 4.0 International License (CC BY-NC-ND 4.0), which permits the noncommercial replication and distribution of the article with the strict proviso that no changes or edits are made and the original work is properly cited (including links to both the formal publication through the relevant DOI and the license). See: https://creativecommons.org/licenses/by-nc-nd/4.0/.

\section{References}

1. Mein JR, Dolnikowski GG, Ernst H, et al. Enzymatic formation of apo-carotenoids from the xanthophyll carotenoids lutein, zeaxanthin and beta-cryptoxanthin by ferret carotene-9',10'-monooxygenase. Arch Biochem Biophys 2011;506:109-21.

2. Fiedor J, Burda K. Potential role of carotenoids as antioxidants in human health and disease. Nutrients 2014;6:466-88.

3. Lietz G, Oxley A, Boesch-Saadatmandi C, et al. Importance of beta,beta-carotene 15,15'-monooxygenase 1 (BCMO1) and beta,beta-carotene 9',10'-dioxygenase 2 (BCDO2) in nutrition and health. Mol Nutr Food Res 2012;56:241-50.

4. Leenders M, Leufkens AM, Siersema PD, et al. Plasma and dietary carotenoids and vitamins $\mathrm{A}, \mathrm{C}$ and $\mathrm{E}$ and risk of colon and rectal cancer in the European Prospective Investigation into Cancer and Nutrition. Int J Cancer 2014;135:2930-9.

5. Eroglu A, Harrison EH. Carotenoid metabolism in mammals, including man: formation, occurrence, and function of apocarotenoids. J Lipid Res 2013;54:1719-30.

6. Hu KQ, Liu C, Ernst H, et al. The biochemical characterization of ferret carotene- 9 ', $10^{\prime}$-monooxygenase catalyzing cleavage of carotenoids in vitro and in vivo. $\mathrm{J}$ Biol Chem 2006;281:19327-38.

7. Ip BC, Liu C, Lichtenstein AH, et al. Lycopene and apo-10'-lycopenoic acid have differential mechanisms of protection against hepatic steatosis in beta-carotene-9',10'oxygenase knockout male mice. J Nutr 2015;145:268-76.

8. Liu C, Bronson RT, Russell RM, et al. beta-Cryptoxanthin supplementation prevents cigarette smoke-induced lung inflammation, oxidative damage, and squamous metaplasia in ferrets. Cancer Prev Res (Phila) 2011;4:1255-66.

9. Kohno H, Taima M, Sumida T, et al. Inhibitory effect of mandarin juice rich in beta-cryptoxanthin and hesperidin on 4-(methylnitrosamino)-1-(3-pyridyl)-1-butanoneinduced pulmonary tumorigenesis in mice. Cancer Lett 
2001;174:141-50.

10. Lian F, Hu KQ, Russell RM, et al. Beta-cryptoxanthin suppresses the growth of immortalized human bronchial epithelial cells and non-small-cell lung cancer cells and up-regulates retinoic acid receptor beta expression. Int J Cancer 2006;119:2084-9.

11. Takayanagi K, Morimoto S, Shirakura Y, et al. Mechanism of visceral fat reduction in Tsumura Suzuki obese, diabetes (TSOD) mice orally administered beta-cryptoxanthin from Satsuma mandarin oranges (Citrus unshiu Marc). J Agric Food Chem 2011;59:12342-51.

12. Iskandar AR, Liu C, Smith DE, et al. beta-cryptoxanthin restores nicotine-reduced lung SIRT1 to normal levels and inhibits nicotine-promoted lung tumorigenesis and emphysema in A/J mice. Cancer Prev Res (Phila) 2013;6:309-20.

13. Kobori M, Ni Y, Takahashi Y, et al. beta-cryptoxanthin alleviates diet-induced nonalcoholic steatohepatitis by suppressing inflammatory gene expression in mice. PLoS One 2014;9:e98294.

14. Männistö S, Smith-Warner SA, Spiegelman D, et al. Dietary carotenoids and risk of lung cancer in a pooled analysis of seven cohort studies. Cancer Epidemiol Biomarkers Prev 2004;13:40-8.

15. Lim JY, Liu C, Hu KQ, et al. Dietary beta-cryptoxanthin inhibits high-refined carbohydrate diet-induced fatty liver via differential protective mechanisms depending on carotenoid cleavage enzymes in male mice. J Nutr 2019;149:1553-64.

16. Lim JY, Liu C, Hu KQ, et al. Xanthophyll betacryptoxanthin inhibits highly refined carbohydrate dietpromoted hepatocellular carcinoma progression in mice. Mol Nutr Food Res 2020;64:e1900949.

17. Amengual J, Lobo GP, Golczak M, et al. A mitochondrial enzyme degrades carotenoids and protects against oxidative stress. FASEB J 2011;25:948-59.

18. Umegaki K, Aoshima M, Hirota S, et al. Simultaneous dietary supplementation of sodium cholate and betacarotene markedly enhances accumulation of beta-carotene in mice. J Nutr 1995;125:3081-6.

19. Breithaupt DE, Weller P, Wolters M, et al. Plasma response to a single dose of dietary beta-cryptoxanthin esters from papaya (Carica papaya L.) or non-esterified beta-cryptoxanthin in adult human subjects: a comparative study. Br J Nutr 2003;90:795-801.

20. Abridged list ordered by nutrient content in household measure. Available online: https://www.nal.usda.gov/sites/ www.nal.usda.gov/files/cryptoxanthin.pdf
21. Xia H, Liu C, Li CC, et al. Dietary tomato powder inhibits high-fat diet-promoted hepatocellular carcinoma with alteration of gut microbiota in mice lacking carotenoid cleavage enzymes. Cancer Prev Res (Phila) 2018;11:797-810.

22. Ip BC, Hu KQ, Liu C, et al. Lycopene metabolite, apo-10'-lycopenoic acid, inhibits diethylnitrosamineinitiated, high fat diet-promoted hepatic inflammation and tumorigenesis in mice. Cancer Prev Res (Phila) 2013;6:1304-16.

23. Livak KJ, Schmittgen TD. Analysis of relative gene expression data using real-time quantitative PCR and the 2-[Delta][Delta]CT method. Methods 2001;25:402-8.

24. Hessel S, Eichinger A, Isken A, et al. CMO1 deficiency abolishes vitamin A production from beta-carotene and alters lipid metabolism in mice. J Biol Chem 2007;282:33553-61.

25. Sheedfar F, Di Biase S, Koonen D, et al. Liver diseases and aging: friends or foes? Aging Cell.2013;12:950-4.

26. Wu L, Guo X, Lyu Y, et al. Targeted metabolomics reveals abnormal hepatic energy metabolism by depletion of betacarotene oxygenase 2 in mice. Sci Rep 2017;7:14624.

27. Tsuchiya H. Retinoids as promising treatment for non-alcoholic fatty liver disease. Yakugaku Zasshi 2012;132:903-9.

28. Tsuchiya H, Ikeda Y, Ebata Y, et al. Retinoids ameliorate insulin resistance in a leptin-dependent manner in mice. Hepatology 2012;56:1319-30.

29. Brun PJ, Yang KJ, Lee SA, et al. Retinoids: potent regulators of metabolism. Biofactors 2013;39:151-63.

30. Amengual J, Widjaja-Adhi MA, Rodriguez-Santiago $\mathrm{S}$, et al. Two carotenoid oxygenases contribute to mammalian provitamin A metabolism. J Biol Chem 2013;288:34081-96.

31. Lim JY, Wang XD. Mechanistic understanding of $\beta$-cryptoxanthin and lycopene in cancer prevention in animal models. Biochim Biophys Acta Mol Cell Biol Lipids 2020. [Epub ahead of print].

32. Ford NA, Elsen AC, Erdman JW Jr. Genetic ablation of carotene oxygenases and consumption of lycopene or tomato powder diets modulate carotenoid and lipid metabolism in mice. Nutr Res 2013;33:733-42.

33. Kelly ME, Ramkumar S, Sun W, et al. The biochemical basis of vitamin A production from the asymmetric carotenoid beta-cryptoxanthin. ACS Chem Biol 2018;13:2121-9.

34. Furr HC, Clark RM. Transport, uptake, and target tissue storage of carotenoids. In: Krinsky NI, Mayne ST, Sies 
H. editors. Carotenoids in health and disease. New York: Marcel Dekker, Inc., 2004:229-78.

35. Purushotham A, Schug TT, Xu Q, et al. Hepatocytespecific deletion of SIRT1 alters fatty acid metabolism and results in hepatic steatosis and inflammation. Cell Metab 2009;9:327-38.

36. Nascimento AF, Ip BC, Luvizotto RAM, et al. Aggravation of nonalcoholic steatohepatitis by moderate alcohol consumption is associated with decreased SIRT1 activity in rats. Hepatobiliary Surg Nutr 2013;2:252-9.

37. Chung J, Koo K, Lian F, et al. Apo-10'-lycopenoic acid, a lycopene metabolite, increases sirtuin $1 \mathrm{mRNA}$ and protein levels and decreases hepatic fat accumulation in ob/ob mice. J Nutr 2012;142:405-10.

38. Lin HC, Chen YF, Hsu WH, et al. Resveratrol helps recovery from fatty liver and protects against hepatocellular carcinoma induced by hepatitis $\mathrm{B}$ virus $\mathrm{X}$ protein in a mouse model. Cancer Prev Res (Phila) 2012;5:952-62.

39. Derdak Z, Villegas KA, Harb R, et al. Inhibition of p53 attenuates steatosis and liver injury in a mouse model of non-alcoholic fatty liver disease. J Hepatol 2013;58:785-91.

40. Sack MN, Finkel T. Mitochondrial metabolism, sirtuins, and aging. Cold Spring Harb Perspect Biol

Cite this article as: Liu C, Rafacho BPM, Wang XD. Xanthophyll $\beta$-cryptoxanthin treatment inhibits hepatic steatosis without altering vitamin A status in $\beta$-carotene 9',10'-oxygenase knockout mice. HepatoBiliary Surg Nutr 2022;11(2):188-198. doi: 10.21037/hbsn-20-404 2012;4:a013102.

41. Koo SH. Nonalcoholic fatty liver disease: molecular mechanisms for the hepatic steatosis. Clin Mol Hepatol 2013;19:210-5.

42. Ding RB, Bao J, Deng CX. Emerging roles of SIRT1 in fatty liver diseases. Int J Biol Sci 2017;13:852-67.

43. Rodgers JT, Lerin C, Haas W, et al. Nutrient control of glucose homeostasis through a complex of PGC-1alpha and SIRT1. Nature 2005;434:113-8.

44. Rodgers JT, Puigserver P. Fasting-dependent glucose and lipid metabolic response through hepatic sirtuin 1. Proc Natl Acad Sci U S A 2007;104:12861-6.

45. Su Q, Baker C, Christian P, et al. Hepatic mitochondrial and ER stress induced by defective PPAR $\alpha$ signaling in the pathogenesis of hepatic steatosis. Am J Physiol Endocrinol Metab 2014;306:E1264-73.

46. Medina-Gomez G, Gray S, Vidal-Puig A. Adipogenesis and lipotoxicity: role of peroxisome proliferatoractivated receptor gamma (PPARgamma) and PPARgammacoactivator-1 (PGC1). Public Health Nutr 2007;10:1132-7.

47. Takayanagi K. Prevention of adiposity by the oral administration of beta-cryptoxanthin. Front Neurol 2011;2:67. 